\title{
Wave energy potential along the Atlantic coast of Morocco
}

\author{
J.P. Sierra*, C. Martín, C. Mösso, M. Mestres \& R. Jebbad \\ Laboratori d'Enginyeria Marítima,Universitat Politècnica de Catalunya, Jordi Girona 1-3, Mòdul D1, Campus \\ Nord, 08034 Barcelona, Spain
}

Centre Internacional d'Investigació dels Recursos Costaners, Jordi Girona 1-3, Mòdul D1, Campus Nord, 08034

Barcelona, Spain

*joan.pau.sierra@upc.edu; tel. +34 934016467; fax: +34 934011861

Published in: Renewable Energy (2016), vol. 96, pp. 20-32

\begin{abstract}
This study analyses the wave energy resource along the Atlantic coast of Morocco using a 44-year series of data obtained from numerical modeling (hindcasting). The spatial distribution of wave power is analyzed using data from 23 points along that coast. The estimated resources (average wave power up to $30 \mathrm{~kW} / \mathrm{m}$ and average annual wave energy up to $262 \mathrm{MW} \mathrm{h} / \mathrm{m}$ ) are considerable and slightly lower than at the neighboring Canary Islands. The central part of this area (between latitudes $29^{\circ} 30^{\prime} \mathrm{N}$ and $34^{\circ} \mathrm{N}$ ) is the most productive, while in the northern and southern parts the resource is significantly lower due to the shadow effect of the Iberian Peninsula and the Canary Islands, respectively. The study of the temporal variability indicates a considerable seasonal trend, being the wave energy resource over four times greater in winter than in summer. Moreover, the power matrices of two wave energy converters (WECs) are considered to estimate the average power output at all the studied points. Finally, a multi-criteria analysis is carried out considering five different factors in order to select the best places for WEC deployment.
\end{abstract}

\section{Introduction}

The energetic needs of the planet are continuously growing due to the increase of population and the emergence of new energy-demanding activities. This is particularly critical in emergent counties like Morocco, in which this situation might be aggravated by the lack of fossil fuel reserves. As a consequence, the development of renewable energies in emergent countries is crucial for both environmental and economic issues.

According to data from 2012 [1], about $90 \%$ of the energy production in Morocco is from thermal origin, while the other $10 \%$ is from renewable sources, mainly hydraulic and wind energy. The energetic sector shows a large dependence from external energy sources, which account for $97 \%$ of primary energy sources and $15 \%$ for electric power [1].

Morocco presents a high potential for renewable energies, and some studies have analyzed the availability of energies due to wind [2-4] and solar radiation [5-6] in this country. Nevertheless, as far as the authors know, there are no specific studies addressing the potential of wave energy there.

Some studies assessed the wave energy resource in the whole Mediterranean. Thus, [7] found at the Mediterranean Coast of Morocco wave energy powers between $2 \mathrm{~kW} / \mathrm{m}$ and $6 \mathrm{~kW} / \mathrm{m}$, while [8] estimated a mean wave power of $6.3 \mathrm{~kW} / \mathrm{m}$ at a point in the Moroccan Mediterranean.

A number of studies have assessed the wave resource in islands located in the Atlantic Ocean, not far from the Moroccan coast, like the Canary Islands [9-12], Madeira [13-14] or Azores Islands [15], or all of these plus Iceland [16]. Other research has focused on the Northeast Atlantic, mainly in the 
United Kingdom [17-19], France [20-21], Portugal [22-24] and Spain [25-28] or several places at a time [29]. These studies found a considerable potential of wave energy in those areas. Moreover, it was estimated that the annual gross theoretical wave power is more significant on the western coasts of the continents, due to the prevalence of west-to-east winds [26, 28-32].

Considering the potential of nearby areas, wave energy could be a good alternative to reduce the dependence of Morocco on fossil fuels, as well as to contribute to reduce greenhouse gas emissions. Moreover, besides energy generation, wave-energy farms can be used for coastal protection in order to limit erosion processes [29, 33].

This paper focuses on the assessment of wave power potential and wave energy yield around the Atlantic coast of Morocco. Section 2 briefly describes the study area and presents the available data and the methodology used. In Section 3 the wave energy resource along the Atlantic coast of Morocco is assessed, while in Section 4 the results are discussed and the best places for deploying Wave Energy Converters (WECs) are identified. Finally, the conclusions of the paper are presented in Section 5.

\section{Data and methods}

\subsection{Study area and available wave data}

Morocco, located in the northwest of Africa, has a long coast (more than 1,800 km) facing the Mediterranean Sea (from the Algerian border to the strait of Gibraltar) and the Atlantic Ocean (from this strait to the limit of Western Sahara). This last stretch is the study area $\left(27^{\circ} 40^{\prime}-35^{\circ} 48^{\prime} \mathrm{N}, 13^{\circ} 11^{\prime}-\right.$ $5^{\circ} 53^{\prime} \mathrm{W}$ ) with an approximate length of $1,300 \mathrm{~km}$ (Figure 1).

Waves arriving at the Moroccan Atlantic coast have their origin in the Azores islands, where winds of large intensity and duration generate high waves that propagate for long distances, reaching that

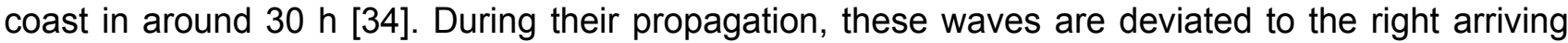
almost perpendicular to the coast and reducing their power [35]. On the northernmost part of this coast, waves are reduced by the shelter provided by the SW corner of the Iberian Peninsula. On the southernmost area, the Canary Islands also contribute to reduce the magnitude of the incoming waves.

The data used for this study correspond to the 44-year hindcasting wave climate database (19582001) from the European HIPOCAS project [36-37]. This wave data set was obtained using the WAM model [38] forced by the wind output of the REMO regional atmospheric model [39], which in turn was forced by the global atmospheric reanalysis carried out by the U.S. National Centers for Environmental Prediction (NCEP). The HIPOCAS database has been extensively validated for wind, wave and sea-level parameters [40-41]. This simulation, like most, has some limitations in terms of properly reproducing certain storm events, but it generally reproduces mean values quite well [42]. With a resolution of $0.25^{\circ} \times 0.25^{\circ}$ and three-hourly data, this database offers homogeneous longterm data and a higher spatial coverage than that obtained with single-point observations (e.g. buoys). Moreover, data from the HIPOCAS project have previously been used to characterize wave energy potential in various areas [10, 26-27, 30-31].

A total of 23 points are analyzed for investigating their wave energy potential. The location of these points is presented in Figure 1, while their geographical coordinates, water depths and distances to the coast are provided in Table 1. These last two data were obtained from nautical charts and the values shown in the table are only approximate. It can be noticed that all the points, except P17 (35 $\mathrm{m})$ and P20 $(40 \mathrm{~m})$ have water depths greater than, or equal to $50 \mathrm{~m}$. On the other hand, the distances to the coast are very variable, ranging from $5 \mathrm{~km}$ (P1) to $52 \mathrm{~km}$ (P6 and P19), with 14 points being located at distances smaller than $25 \mathrm{~km}$ while the other 9 are farther away from the coast. Although some distances could seem too large, they can be considered viable for a future 
farm location since they are deemed feasible for the offshore wind industry, with some projects operating (or planned to be installed) at distances from the shore between 79 and $112 \mathrm{~km} \mathrm{[29].}$

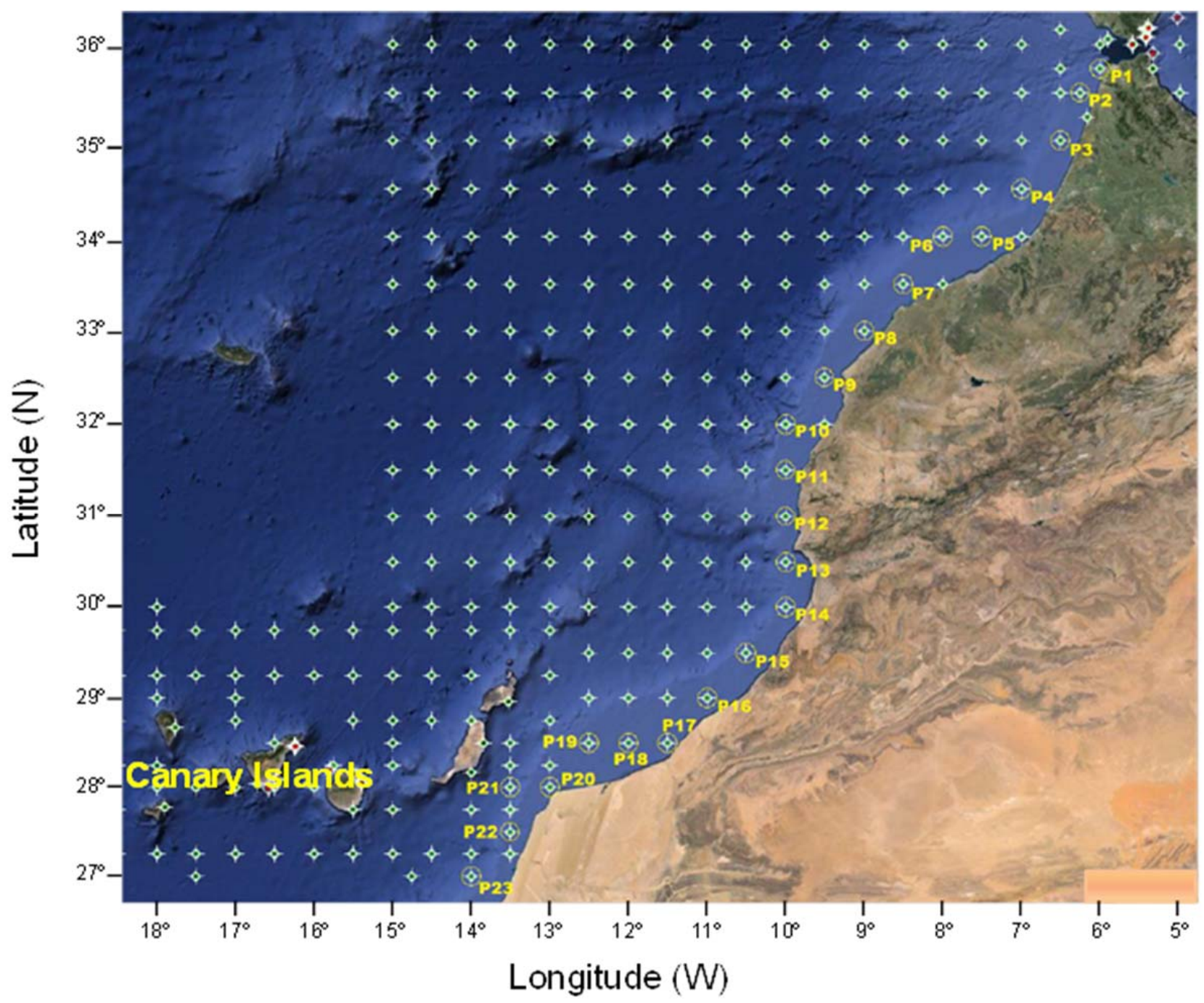

Figure 1. Map of the Moroccan Coast with the location of the 23 studied points.

\begin{tabular}{|c|c|c|c|c|}
\hline Point & Longitude (W) & Latitude (N) & Depth $\mathbf{( m )}$ & Distance (km) \\
\hline P1 & $6^{\circ} 00^{\prime}$ & $35^{\circ} 45^{\prime}$ & 60 & 5 \\
\hline P2 & $6^{\circ} 15^{\prime}$ & $35^{\circ} 30^{\prime}$ & 110 & 18 \\
\hline P3 & $6^{\circ} 30^{\prime}$ & $35^{\circ} 00^{\prime}$ & 130 & 21.5 \\
\hline P4 & $7^{\circ} 00^{\prime}$ & $34^{\circ} 30^{\prime}$ & 200 & 38 \\
\hline P5 & $7^{\circ} 30^{\prime}$ & $34^{\circ} 00^{\prime}$ & 140 & 31.5 \\
\hline P6 & $8^{\circ} 00^{\prime}$ & $34^{\circ} 00^{\prime}$ & 200 & 52 \\
\hline P7 & $8^{\circ} 30^{\prime}$ & $33^{\circ} 30^{\prime}$ & 60 & 22 \\
\hline P8 & $9^{\circ} 00^{\prime}$ & $33^{\circ} 00^{\prime}$ & 90 & 16.5 \\
\hline P9 & $9^{\circ} 30^{\prime}$ & $32^{\circ} 30^{\prime}$ & 60 & 20 \\
\hline P10 & $10^{\circ} 00^{\prime}$ & $32^{\circ} 00^{\prime}$ & 500 & 45 \\
\hline P11 & $10^{\circ} 00^{\prime}$ & $31^{\circ} 30^{\prime}$ & 70 & 17.5 \\
\hline P12 & $10^{\circ} 00^{\prime}$ & $31^{\circ} 00^{\prime}$ & 80 & 16 \\
\hline P13 & $10^{\circ} 00^{\prime}$ & $30^{\circ} 30^{\prime}$ & 120 & 16.5 \\
\hline
\end{tabular}




\begin{tabular}{|c|c|c|c|c|}
\hline P14 & $10^{\circ} 00^{\prime}$ & $30^{\circ} 00^{\prime}$ & 125 & 23.5 \\
\hline P15 & $10^{\circ} 30^{\prime}$ & $29^{\circ} 30^{\prime}$ & 120 & 33 \\
\hline P16 & $11^{\circ} 00^{\prime}$ & $29^{\circ} 00^{\prime}$ & 60 & 21.5 \\
\hline P17 & $11^{\circ} 30^{\prime}$ & $28^{\circ} 30^{\prime}$ & 35 & 13 \\
\hline P18 & $12^{\circ} 00^{\prime}$ & $28^{\circ} 30^{\prime}$ & 50 & 37 \\
\hline P19 & $12^{\circ} 30^{\prime}$ & $28^{\circ} 30^{\prime}$ & 95 & 52 \\
\hline P20 & $13^{\circ} 00^{\prime}$ & $28^{\circ} 00^{\prime}$ & 40 & 9 \\
\hline P21 & $13^{\circ} 30^{\prime}$ & $28^{\circ} 00^{\prime}$ & 350 & 47 \\
\hline P22 & $13^{\circ} 30^{\prime}$ & $27^{\circ} 30^{\prime}$ & 85 & 24 \\
\hline P23 & $14^{\circ} 00^{\prime}$ & $27^{\circ} 00^{\prime}$ & 350 & 49 \\
\hline
\end{tabular}

Table 1. Locations, water depths and distances to the coast for the points considered. Note: Depths and distances have been obtained from nautical charts and they are approximate values.

\subsection{Methodology}

Wave power can be obtained using the following deep-water expression:

$$
P=\frac{\rho g^{2}}{64 \pi} H_{s}^{2} T_{e}=0.491 H_{s}^{2} T_{e}
$$

where $P$ is the is the wave power per unit of crest length $(\mathrm{kW} / \mathrm{m}), H_{s}$ is the significant wave height, $T_{e}$ is the energy period, $\rho$ is the density of seawater (assumed to be $1025 \mathrm{~kg} / \mathrm{m}^{3}$ ) and $g$ is the gravitational acceleration. $T_{e}$ is computed as a function of spectral moments:

$$
T_{e}=\frac{m_{-1}}{m_{0}}
$$

The database used in this work does not provide information on spectral moments or spectral shape, and sea states are specified in terms of significant wave height $H_{s}$ and peak period $T_{p}$, so $T_{e}$ must be estimated from other variables. One approach when $T_{p}$ is known is to assume the following:

$$
T_{e}=\alpha T_{p}
$$

where $\alpha$ is a coefficient whose value depends on the shape of the wave spectrum ( 0.86 for a Pierson-Moskowitz spectrum and increasing towards unity with decreasing spectral width) [43]. Taking into account that wave spectra in this area are rather wide due to the combined presence of sea and swell sea states, as suggested by [43-44] a conservative value of $T_{e}=0.9 T_{p}$ was used to assess the wave energy resource.

Most of the points analyzed are located at depths greater than $90 \mathrm{~m}$, so for most of the wave periods they are in deep waters and thus equation (1) can be applied without restrictions. In some cases the use of equation (1) introduces a certain error, when the points are located in intermediate waters for some sea states (those with longer wave periods). Nevertheless, taking into account the inaccuracy introduced by the use of equation (3) and the conservative value adopted to assess $T_{e}$, the use of expression (1) in those points can be considered acceptable.

With Equations (1) and (3), the total wave energy resource at a point can be assessed, allowing the computation of the power average at each point. As mentioned above, this assessment of wave 
power uses data sets from 44-year numerical simulations, which are long enough to account for inter-annual variability.

Besides the amount of wave power and potentially available energy, another factor to consider when selecting a site for wave energy converter (WEC) deployment is its temporal variability at different time scales (daily, monthly and seasonal). Sites with a steady wave energy flux are preferable to those with unsteady wave conditions since they are more reliable and show a greater efficiency.

Among the coefficients proposed to assess the temporal variability in wave power at a specific location we use three proposed by Cornett [43]: the coefficient of variation (COV), the seasonal variability index (SV) and the monthly variability index (MV).

The COV is obtained by dividing the standard deviation $(\sigma)$ of the power time series $(F(t))$ by the mean power $(\mu)$ :

$$
\operatorname{COV}(F)=\frac{\sigma[F(t)]}{\mu[F(t)]}
$$

The COV would be zero for a fictitious wave power time series with absolutely no variability; from there, its value increases with variability. Values of $0.85-0.9$ indicate that the resource is only moderately unsteady, while values greater than 1.2 denote considerable variability.

The SV is defined as:

$$
S V=\frac{P_{s 1}-P_{s 4}}{P_{\text {year }}}
$$

where $P_{S 1}$ is the mean wave power for the highest-energy season (usually winter) and $P_{S 4}$ is the mean wave power for the lowest-energy season (usually summer), and $P_{\text {year }}$ is the annual mean wave power. The greater the value of SV the larger the seasonal variability, with values lower than 1 indicating moderate seasonal variability.

MV is defined as follows:

$$
M V=\frac{P_{M 1}-P_{M 12}}{P_{\text {year }}}
$$

where $P_{M 1}$ is the mean wave power for the highest-energy month and $P_{M 12}$ is the mean wave power for the lowest-energy month. Obviously, the values of MV are greater than those of SV.

On the other hand, the amount of electric energy delivered by a WEC depends on the average wave energy available at the location of the device, but is also highly dependent on the way in which this energy is scattered amongst the energy bins, defined by intervals of significant wave height and wave energy period [14]. This is because each WEC has its own power matrix, indicating the power output for each energy bin. Thus,

$$
E=\sum_{i=1}^{n_{T}} \sum_{j=1}^{n_{H}} h_{i j} P_{i j}
$$


where $E$ is the WEC energy output per year (in $\mathrm{kW} \mathrm{h}$ ), $h_{i j}$ is the number of hours per year corresponding to the bin defined by the column $\mathrm{j}$ and the row $\mathrm{i}$, while $P_{i j}$ is the electric power (in $\mathrm{kW}$ ) provided in the power matrix of the WEC for the same bin. In this study, two WECs whose development state can be considered mature [29] are used to assess the potential energy production: the Pelamis converter [45], whose principle is attenuator, and the Wave Dragon device [46], whose principle is terminator.

Finally, to assess the WEC efficiency an index usually considered is the capacity factor $C_{f}$, which is computed as:

$$
C_{f}=100 \frac{P_{E}}{P_{W E C \max }}
$$

where $P_{E}$ is the average electric power produced by the WEC at a specific location and $P_{W E C \max }$ is its maximum rated power.

\section{Results}

\subsection{Analysis of wave data}

Before assessing the wave energy, the wave conditions in the area are analyzed. Figure 2 shows the mean $H_{s}$ and $T_{e}$ at the 23 studied points while Table 2 presents a statistical analysis of the significant wave height. It can be observed that the largest significant wave heights are located in the central area of the Atlantic Moroccan coast, while in the northern and southern parts these values are considerably lower due to the aforementioned shadow effects generated respectively by the Iberian Peninsula and the Canary Islands.

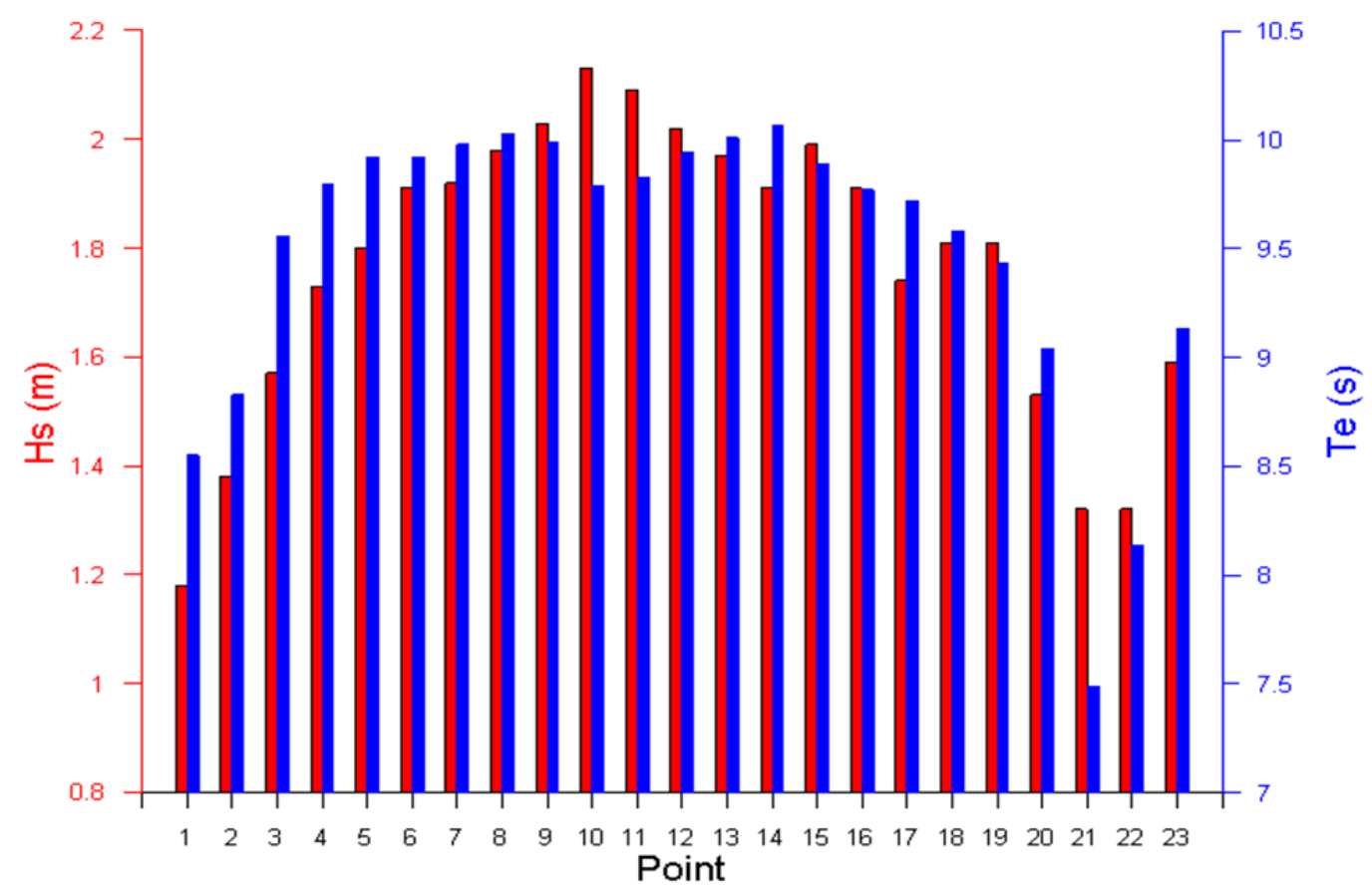


Figure 2. Values of the mean $H_{s}$ and mean $T_{e}$ at the 23 studied points.

\begin{tabular}{|c|c|c|c|c|c|}
\hline Point & Mean $\mathbf{( m )}$ & Maximum $\mathbf{( m )}$ & P. 95 th $\mathbf{( m )}$ & Std Dev $(\mathbf{m})$ & $>\mathbf{2} \mathbf{~ m} \mathbf{( \% )}$ \\
\hline P1 & 1.18 & 8.6 & 2.6 & 0.72 & 11.0 \\
\hline P2 & 1.38 & 9.5 & 2.9 & 0.79 & 16.2 \\
\hline P3 & 1.57 & 9.9 & 3.2 & 0.86 & 23.2 \\
\hline P4 & 1.73 & 10.2 & 3.5 & 0.92 & 29.2 \\
\hline P5 & 1.80 & 9.7 & 3.6 & 0.91 & 32.6 \\
\hline P6 & 1.91 & 10.1 & 3.8 & 0.95 & 37.4 \\
\hline P7 & 1.92 & 9.6 & 3.7 & 0.91 & 37.7 \\
\hline P8 & 1.98 & 9.6 & 3.8 & 0.92 & 40.7 \\
\hline P9 & 2.03 & 10.5 & 3.9 & 0.94 & 42.8 \\
\hline P10 & 2.13 & 10.9 & 3.9 & 0.93 & 49.5 \\
\hline P11 & 2.09 & 10.6 & 3.8 & 0.90 & 47.7 \\
\hline P12 & 2.02 & 10.4 & 3.7 & 0.87 & 43.8 \\
\hline P13 & 1.97 & 10.1 & 3.6 & 0.86 & 40.8 \\
\hline P14 & 1.91 & 9.8 & 3.5 & 0.83 & 37.4 \\
\hline P15 & 1.99 & 9.6 & 3.6 & 0.84 & 42.7 \\
\hline P16 & 1.91 & 8.8 & 3.4 & 0.79 & 38.6 \\
\hline P17 & 1.74 & 8.0 & 3.1 & 0.72 & 29.9 \\
\hline P18 & 1.81 & 8.0 & 3.3 & 0.74 & 33.5 \\
\hline P19 & 1.81 & 7.6 & 3.2 & 0.73 & 33.8 \\
\hline P20 & 1.53 & 5.6 & 2.7 & 0.59 & 19.8 \\
\hline P21 & 1.32 & 6.4 & 2.4 & 0.60 & 13.6 \\
\hline P22 & 1.32 & 6.0 & 2.3 & 0.50 & 10.7 \\
\hline P23 & 1.59 & 6.4 & 2.8 & 0.61 & 22.4 \\
\hline
\end{tabular}

Table 2. Significant wave height statistics corresponding to the 23 studied points.

From the analysis of the $H_{s}$ mean values, it can be noticed that the sector between points P9 and $\mathrm{P} 12$ has the highest values, all of them exceeding $2 \mathrm{~m}$, particularly at P10 with $2.13 \mathrm{~m}$ and P11, with $2.09 \mathrm{~m}$. The neighbouring stretches (from P6 to P8 and from P13 to P16) show slightly smaller mean wave heights, with values between 1.91 and $1.98 \mathrm{~m}$. The northernmost (P1 to P3) and southernmost (P20 to P23) areas present the lowest values, which are less than $1.6 \mathrm{~m}$. Regarding the energy period, the largest mean value is found at P14 with $10.07 \mathrm{~s}$, followed by P8 with $10.03 \mathrm{~s}$ and $\mathrm{P} 13$ with $10.01 \mathrm{~s}$. In the stretch between P4 and P17 all the values are larger than $9.7 \mathrm{~s}$. Surprisingly, the two most energetic points show some of the lowest mean $T_{e}$ values with $9.79 \mathrm{~s}$ (P10) and $9.83 \mathrm{~s} \mathrm{(P11).}$ 

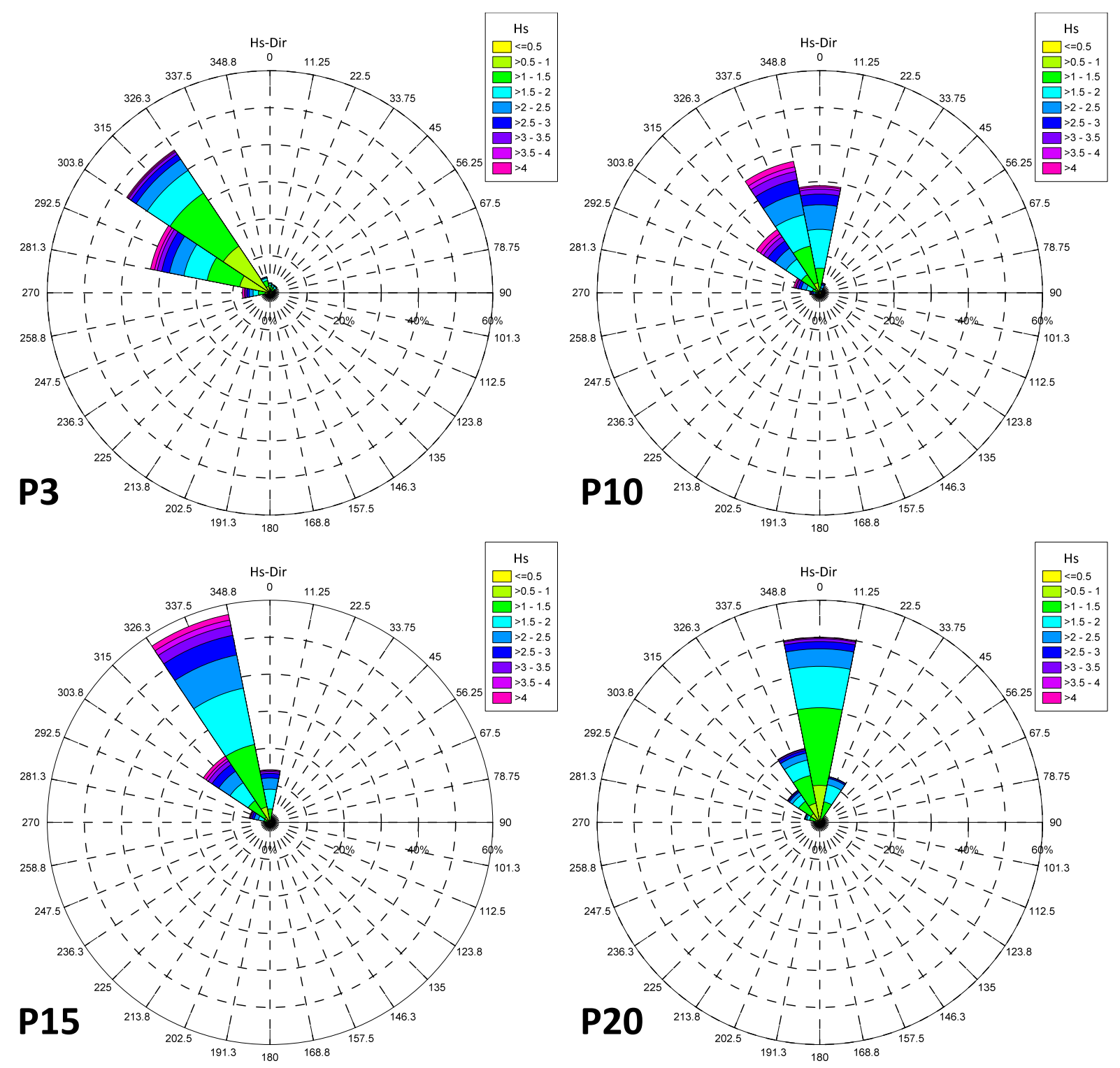

Figure 3. Wave roses distributed in $22.5^{\circ}$ bins corresponding to points $\mathrm{P} 3, \mathrm{P} 10, \mathrm{P} 15$ and $\mathrm{P} 20$.

The statistical parameters of $H_{s}$ displayed in Table 2 include the average and maximum values, the 95th percentile, the standard deviation and the percentage of values greater than $2 \mathrm{~m}$. As regards to maximum $H_{s}$ values, these are concentrated in the sector P2-P15, with values higher than $9.5 \mathrm{~m}$, with point P10 presenting the maximum value $(10.9 \mathrm{~m})$, followed by $\mathrm{P} 11(10.6 \mathrm{~m})$ and P9 $(10.5 \mathrm{~m})$. The points in the southern part of the studied area (P17-P23) have significantly lower maximum $H_{s}$ values (smaller than or equal to $8 \mathrm{~m}$ ). Regarding the 95th percentile $(95 \%)$ the maximum values are found in the stretch P3-P19, where they are larger than $3 \mathrm{~m}$, peaking at P9 and P10 with $3.9 \mathrm{~m}$. The analysis of the standard deviation values indicates that the larger deviations from the mean $H_{s}$ are located in the sector P4-P11 with values greater than or equal to 0.90 , progressively decreasing towards the ends. This parameter presents particularly low values in the southernmost area (P20$\mathrm{P} 23$ ), ranging between 0.50 and 0.61 . Finally, the significant wave heights greater than $2 \mathrm{~m}$ have also been computed, being again the central area (from P6 to P16) where this value is more exceeded. More than $37 \%$ of the sea states have a $H_{s}$ higher than $2 \mathrm{~m}$ at all these points, particularly at P10 with almost half of the time $(49.5 \%)$ and P11 $(47.7 \%)$. 
In Figure 3 the wave roses of four selected points (spread along the studied area) are presented, showing the directional distribution of the significant wave height. From these wave roses it is evident that almost all the wave energy arriving to this coast comes from the sector between $\mathrm{N}$ and WNW. At P3, the presence of the Iberian Peninsula at the north prevents the existence of waves from the $\mathrm{N}$ and therefore almost all the waves come from NW and WNW, being WNW waves less frequent (33\%) than NW ones (46\%), although they are more energetic. At P10, most of the wave energy is distributed in three directions: $N(29 \%)$, NNW (36\%) and NW (21\%), being the $N$ the direction with smaller waves. At P15 the same three directions concentrate most of the wave energy, although in this case the NNW represents more than $57 \%$ of the waves, followed by NW $(22 \%)$ and $N(14 \%)$. Finally, in the southern part of the studied domain, the presence of the Canary Islands prevents the arrival of swells from the NW and therefore, the N $(50 \%)$ and NNW $(20 \%)$ are the dominant directions.

\subsection{Wave energy resource}

The average wave power (computed with equations (1) and (3)) at the 23 locations is shown in Figure 4 and Table 3. Several areas with different wave energy distributions can be distinguished: a higher-energy area encompassing the central part of the studied domain (from P6 to P15) with annual average wave powers greater than $25 \mathrm{~kW} / \mathrm{m}$ and annual wave energies greater than 218 $\mathrm{MW} \mathrm{h/m;} \mathrm{two} \mathrm{low-energy} \mathrm{areas,} \mathrm{including} \mathrm{both} \mathrm{ends} \mathrm{of} \mathrm{the} \mathrm{studied} \mathrm{domain} \mathrm{(P1-P3} \mathrm{and} \mathrm{P20-P23)}$ with average wave powers lower than $18 \mathrm{~kW} / \mathrm{m}$ and annual wave energies lower than $160 \mathrm{MW} \mathrm{h} / \mathrm{m}$; and two transitional areas with intermediate-energy (P4-P5 and P16-P19) with average powers between $19 \mathrm{~kW} / \mathrm{m}$ and $24 \mathrm{~kW} / \mathrm{m}$ and annual wave energies between $165 \mathrm{MW} \mathrm{h} / \mathrm{m}$ and $205 \mathrm{MW} \mathrm{h} / \mathrm{m}$.

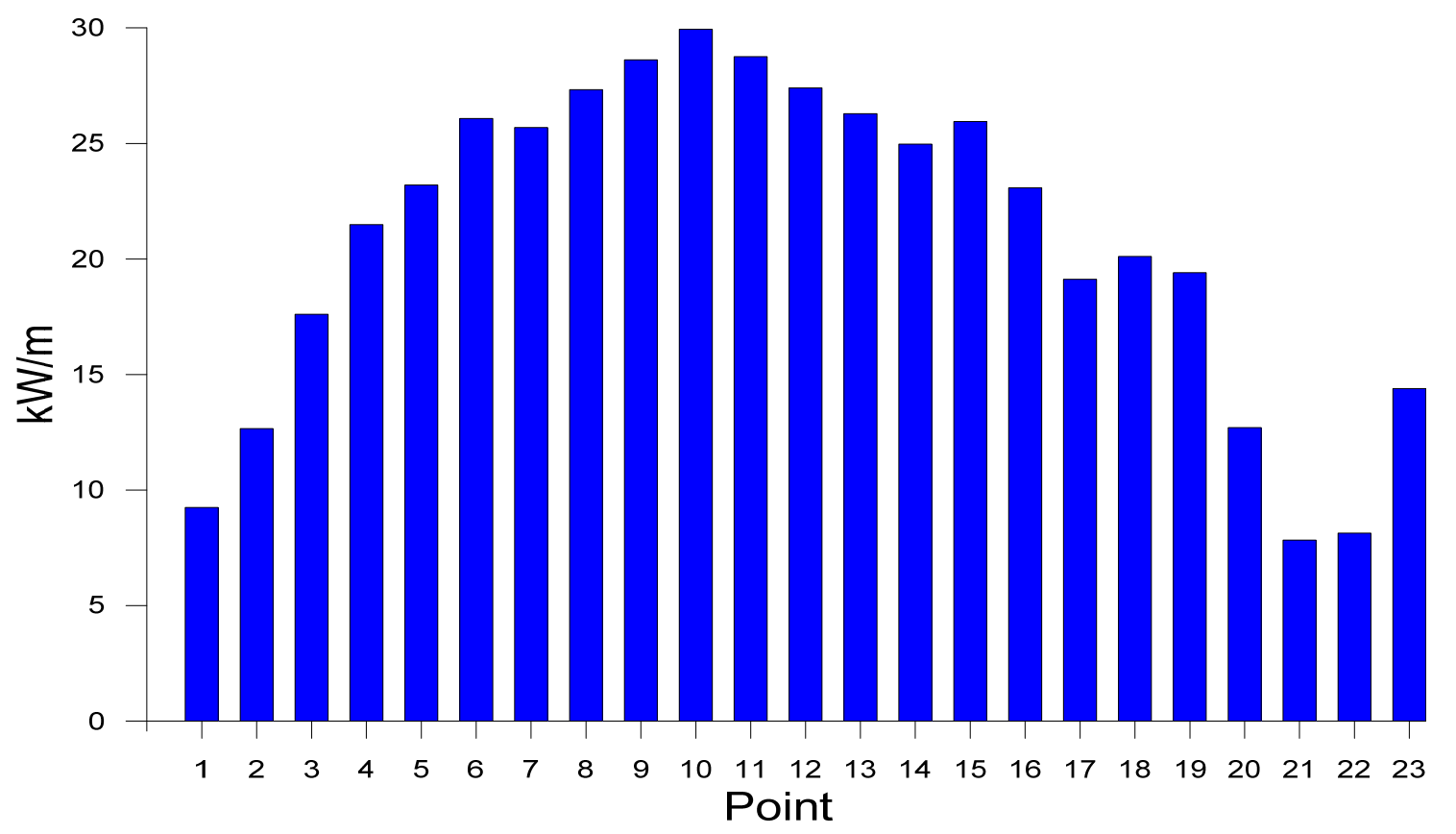

Figure 4. Average values of the wave power per unit width at the 23 studied points.

\begin{tabular}{|c|c|c|c|c|c|}
\hline Point & Mean power (kW/m) & Annual energy (MW h/m) & COV & SV & MV \\
\hline P1 & 9.25 & 81.00 & 2.03 & 1.75 & 1.79 \\
\hline P2 & 12.66 & 110.91 & 1.93 & 1.75 & 1.81 \\
\hline P3 & 17.61 & 154.29 & 1.76 & 1.71 & 1.80 \\
\hline
\end{tabular}




\begin{tabular}{|c|c|c|c|c|c|}
\hline P4 & 21.49 & 188.29 & 1.67 & 1.67 & 1.77 \\
\hline P5 & 23.20 & 203.21 & 1.57 & 1.62 & 1.71 \\
\hline P6 & 26.08 & 228.47 & 1.54 & 1.60 & 1.69 \\
\hline P7 & 25.69 & 225.03 & 1.46 & 1.52 & 1.62 \\
\hline P8 & 27.33 & 239.45 & 1.41 & 1.48 & 1.57 \\
\hline P9 & 28.62 & 250.68 & 1.43 & 1.47 & 1.56 \\
\hline P10 & 29.94 & 262.31 & 1.36 & 1.38 & 1.45 \\
\hline P11 & 28.76 & 251.97 & 1.33 & 1.35 & 1.44 \\
\hline P12 & 27.40 & 239.99 & 1.35 & 1.36 & 1.46 \\
\hline P13 & 26.29 & 230.34 & 1.35 & 1.37 & 1.46 \\
\hline P14 & 24.97 & 218.70 & 1.36 & 1.39 & 1.49 \\
\hline P15 & 25.95 & 227.33 & 1.29 & 1.29 & 1.37 \\
\hline P16 & 23.08 & 202.17 & 1.26 & 1.20 & 1.27 \\
\hline P17 & 19.12 & 167.48 & 1.27 & 1.17 & 1.23 \\
\hline P18 & 20.11 & 176.20 & 1.25 & 1.11 & 1.19 \\
\hline P19 & 19.41 & 170.03 & 1.20 & 1.04 & 1.13 \\
\hline P20 & 12.70 & 111.28 & 1.13 & 0.84 & 0.96 \\
\hline P21 & 7.83 & 68.56 & 1.20 & 0.39 & 0.57 \\
\hline P22 & 8.14 & 71.30 & 1.03 & 0.62 & 0.84 \\
\hline P23 & 14.39 & 126.04 & 1.21 & 1.18 & 1.31 \\
\hline
\end{tabular}

Table 3 . Wave power and variability coefficients at the 23 studied points.

Besides the clear spatial distribution of the wave energy shown in Figure 4, it is also interesting to analyze the temporal variability of the wave power. Figure 5 shows the average monthly wave power at the 23 studied locations. In this figure, a clear seasonal trend can be observed, with energy power reaching its largest values in the winter months (December-February), peaking at all points in January, followed by December and February. On the contrary, during summer months (June-August) wave power drops to its minimum values, while in the rest of the year there is a transition between these two situations. In the southernmost less energetic points this contrast between summer and winter is not as marked and, in particular, at P21 and P22, the points more affected by the presence of the Canary Islands, the distribution of energy is fairly uniform throughout the year.

In Figure 6, the average seasonal wave power at the 23 studied sites is plotted. This plot shows the strong seasonal character of Morocco's wave energy, with a considerable range of variation between seasons, except at the aforementioned P21 and P22 sites. About $43 \%$ of Morocco's annual wave power corresponds to winter, $26 \%$ to spring, $21 \%$ to autumn and $10 \%$ to summer, such that the wave energy resource is more than four times greater in winter than in summer. 

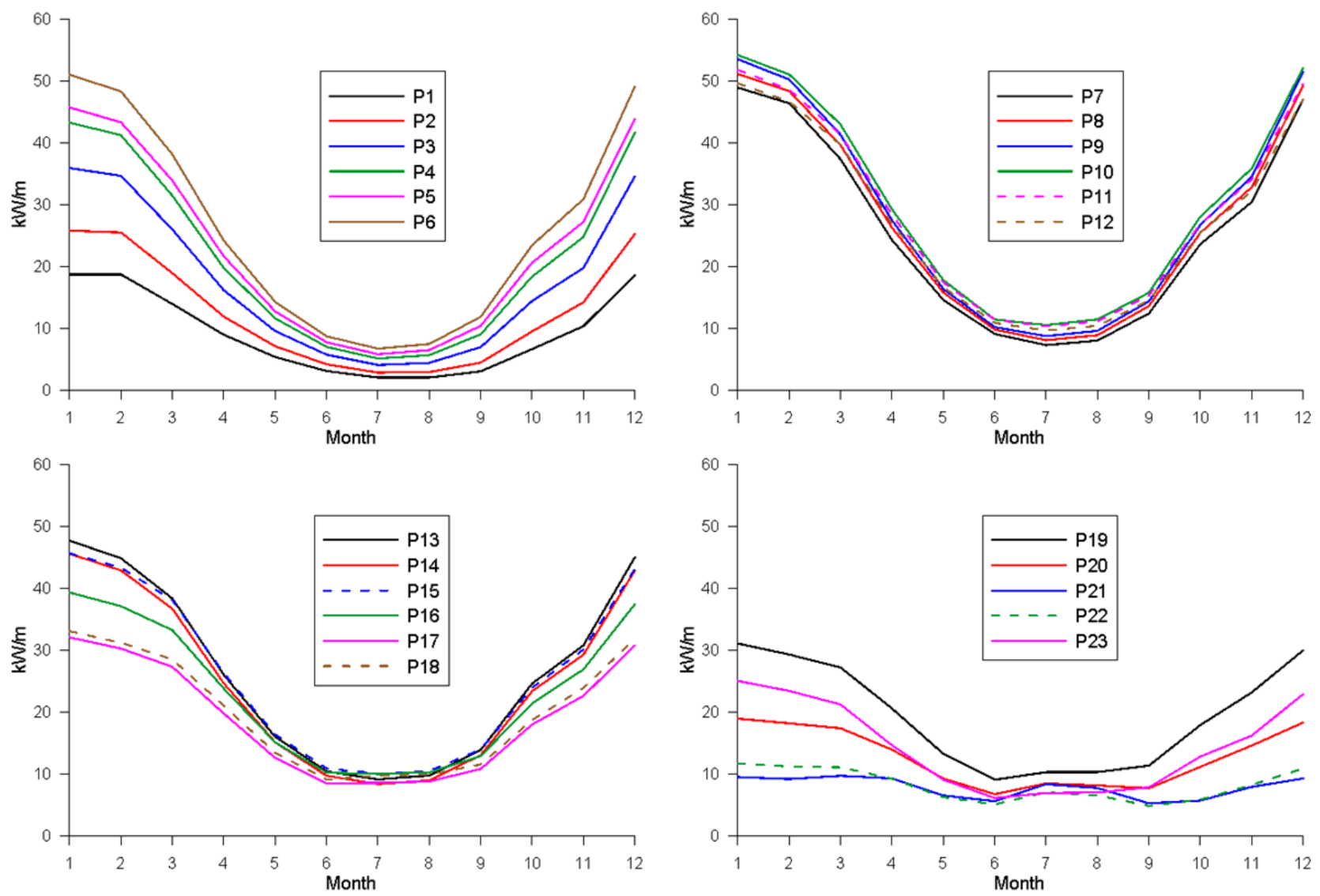

Figure 5. Monthly average values of the wave power per unit width at the 23 studied points.

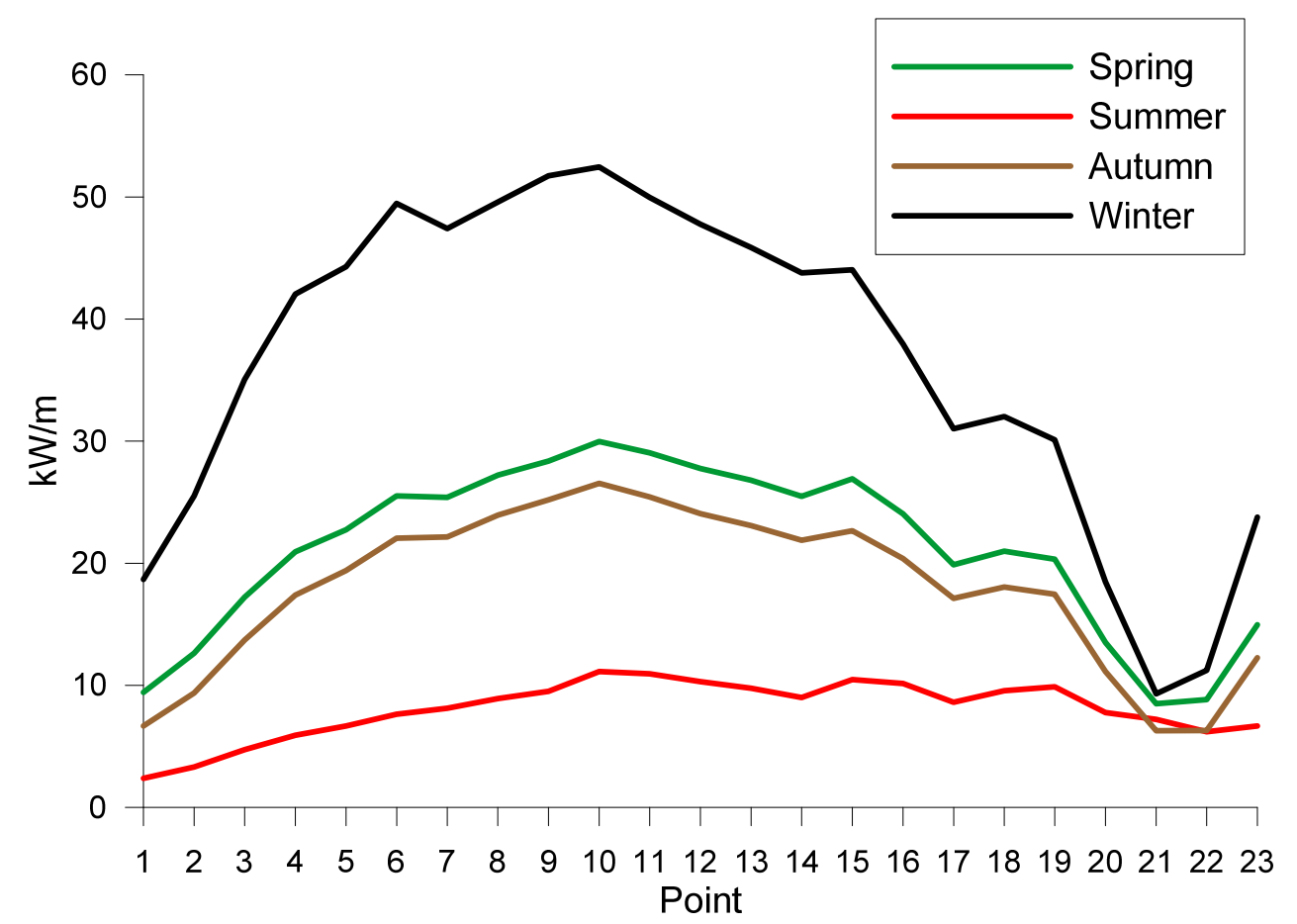

Figure 6. Seasonal average values of the wave power per unit width at the 23 studied points.

In summary, four periods throughout the year can be distinguished from the point of view of the wave energy: a stormy period from November to March, with over $65 \%$ of the annual wave energy (average in all the area); a calm period from May to September with the $19 \%$ of the total wave 
energy; two transitional periods (April and October) with intermediate wave energy conditions, accounting for almost $16 \%$ of the annual wave energy. This concentration of energy in the period between November and March is consistent with similar studies carried out in different areas of the Eastern Atlantic Ocean: Canary Islands [10, 16], Iceland [16], United Kingdom [17] and the Sea of Iroise [47], although in areas like Madeira and Azores Islands [16] or the West coast of France, October was also among the most energetic months. On the contrary, the seasonal distribution of wave energy is more uniform in areas of the Western Atlantic Ocean like Santa Catarina (Brazil) [48].

To conclude the temporal variability analysis the coefficients described in Section 2.2 have been computed and their values are shown in Table 3 and Figure 7. The three coefficients COV, SV and MV show a general decreasing trend from North to South, with some distortions in the southernmost part of the studied area due to the influence of the Canary Islands. Regarding the points with a larger wave energy potential, in the stretch P6-P9 the temporal variability is high, with MV varying between 1.56 and 1.69, SV between 1.47 and 1.60 and COV between 1.43 and 1.54. The following stretch going southwards (P10-P14) present less variability, with COV from 1.33 to 1.36, MV from 1.44 to 1.49 and SV from 1.35 to 1.39. Finally, the points located near the southern end of the coast present the lowest variability coefficients. It is noticeable that P15 and P16, which have a considerable wave energy potential, have relatively low coefficients, in particular P16, with values of 1.20 for SV, 1.26 for COV and 1.27 for MV. Therefore, these points show a priori a good potential for WEC deployment because they combine a significant wave energy resource with a more uniform distribution of the resource throughout the year. Other points located southward from P16 show less temporal variability, but the energy resource is also lower.

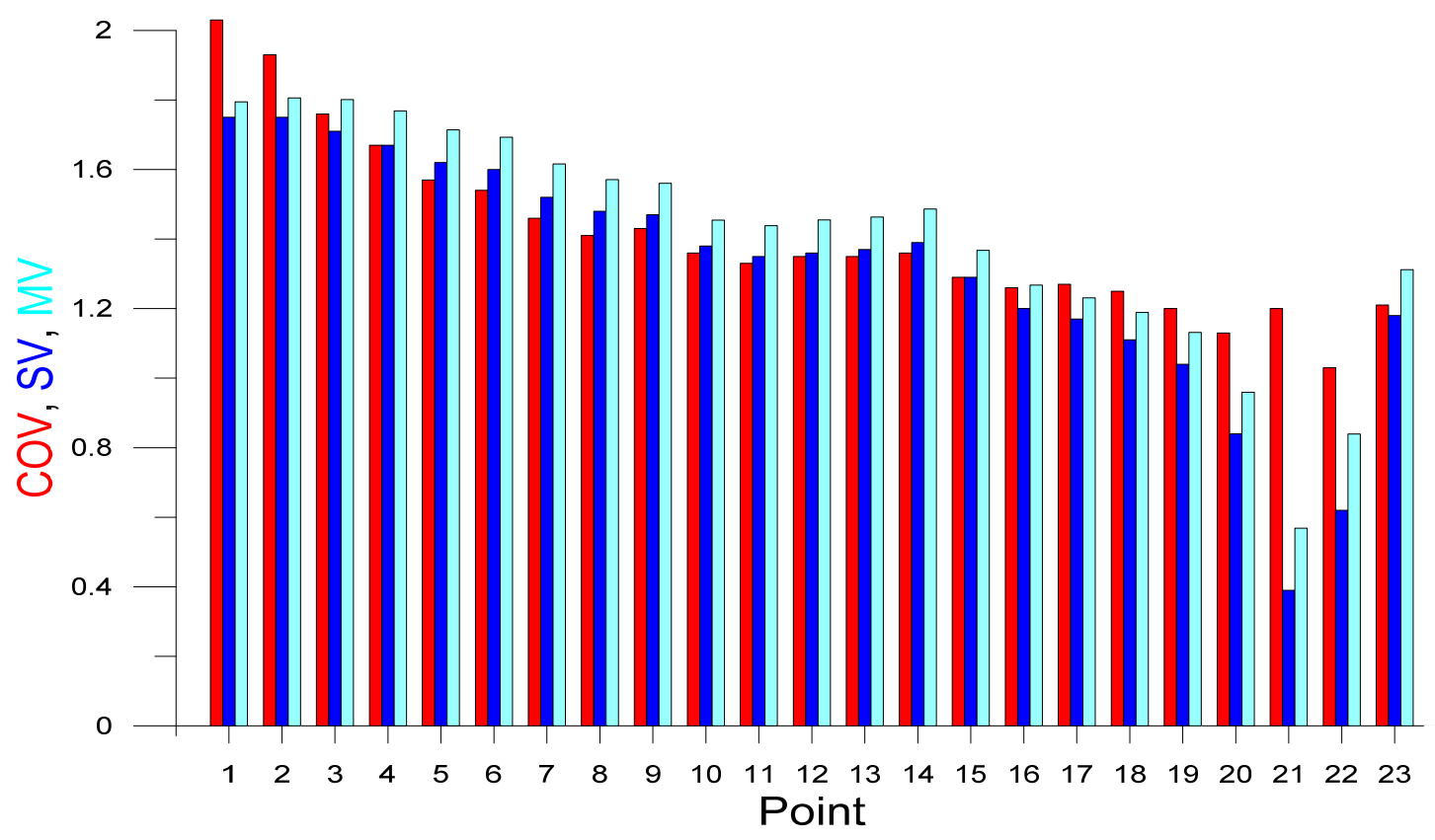

Figure 7 . Variability coefficients at the 23 studied points.

\section{Selection of the best location for WEC deployment}




\subsection{WEC output and performance}

The primary consideration for the deployment of a WEC at a certain site is the amount of wave power available at this point. In the previous section, the central stretch of the studied area (points P6 to P15 and, in particular from P8 to P12) was identified as that offering the greatest wave energy potential. Another factor to take into account in choosing a site for WEC installation is the temporal variability at different scales (daily, monthly and seasonal). Sites with moderate wave energy flux may be preferable than other where energy is higher but more unsteady (and, therefore, less reliable) because WEC efficiency may decrease significantly under more variable wave conditions [43]. In Figure 7 and in the previous Section it was shown that the lowest temporal variability is found in the southern part of the studied area, which is one of the less energetic, while the most energetic central stretch presents a medium temporal variability.
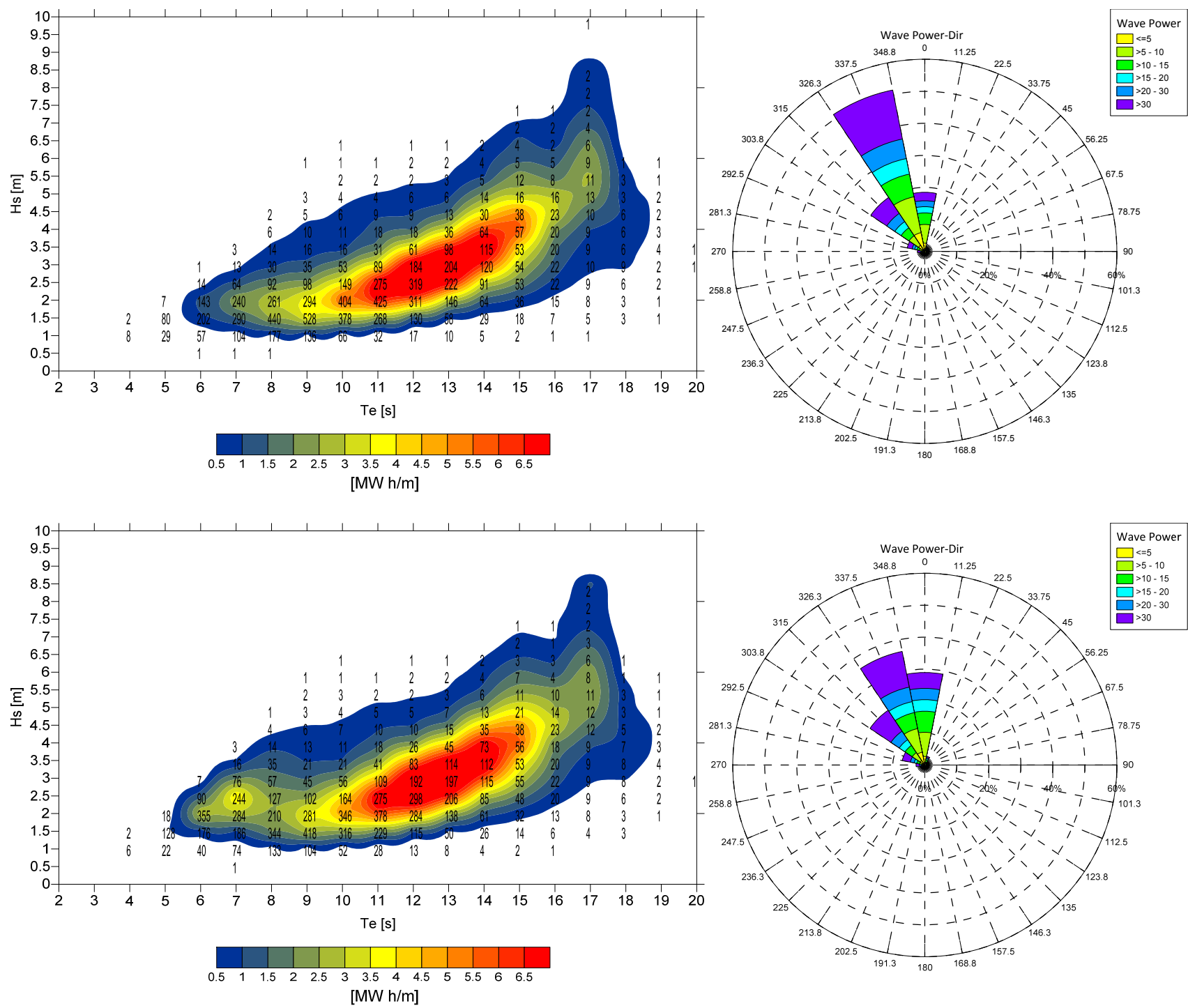

Figure 8. Left: Scatter diagrams showing the various sea states' contribution to the total annual energy at points P9 (top) and P10 (bottom). The color scale represents annual energy per meter of wave front (in MW $\mathrm{h} / \mathrm{m}$ ). Numbers indicate the occurrence of each sea state (in hours per year). Right: Energy roses indicating the directional distribution of wave power. 
Another very important factor for verifying the suitability of a certain site for WECs deployment is the wave energy output delivered by the device installed at this point. The amount of electric energy delivered by a WEC depends on the average energy available at the location but also on the way in which this energy is scattered among the energy bins, defined by intervals of significant wave height and wave energy period [14]. This is because each WEC has its own power matrix, with a power output for each energy bin.

With this aim, the scatter diagrams of $H_{s}$ and $T_{e}$ have been obtained for the 23 studied points and some of them (those corresponding to the most energetic and therefore the a priori most suitable sites) are shown in Figures 8 and 9.
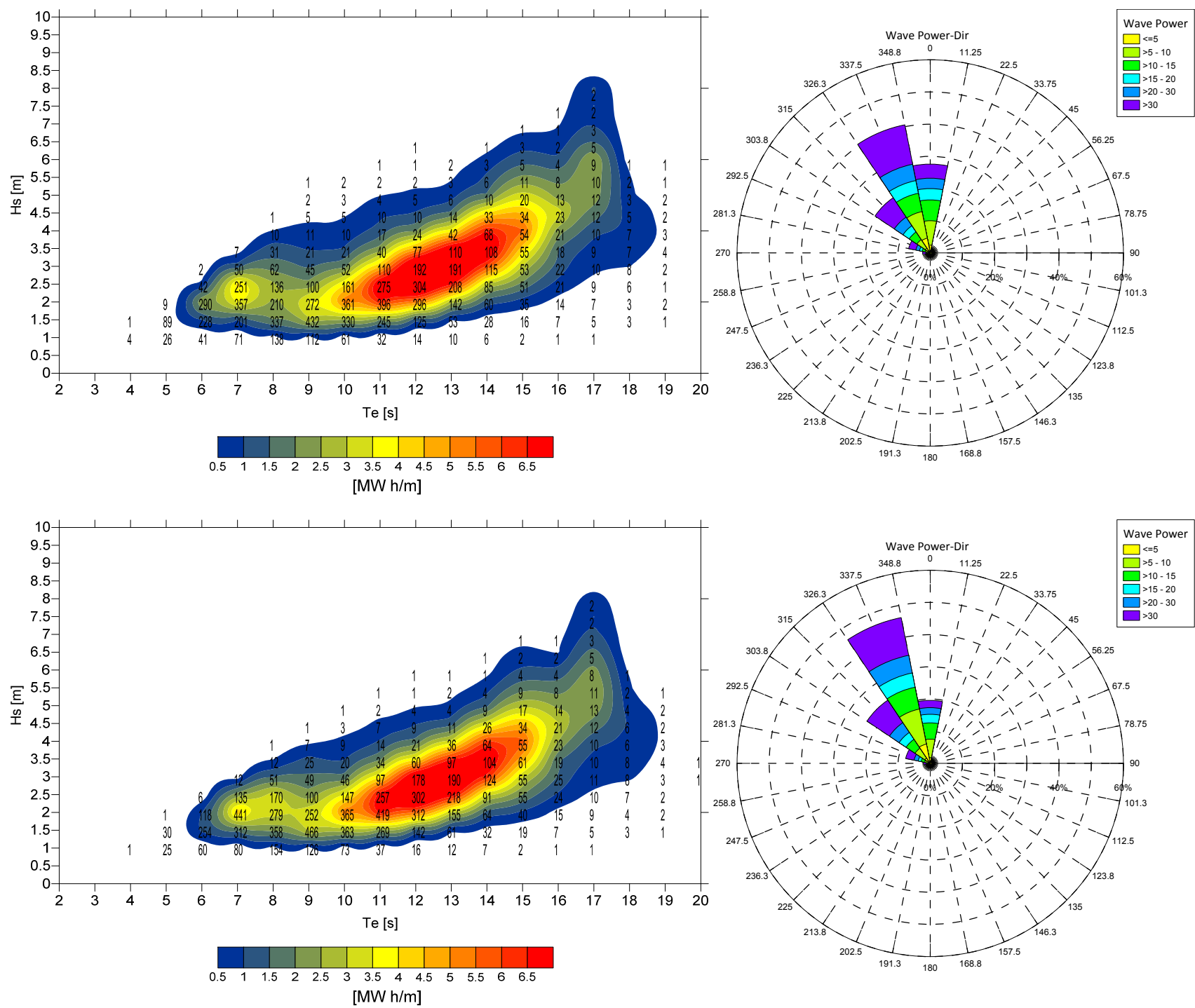

Figure 9. Left: Scatter diagrams showing the various sea states' contribution to the total annual energy at points P11 (top) and P12 (bottom). The color scale represents annual energy per meter of wave front (in MW $\mathrm{h} / \mathrm{m}$ ). Numbers indicate the occurrence of each sea state (in hours per year). Right: Energy roses indicating the directional distribution of wave power. 
Figures 8 and 9 show the total annual energy that could be extracted from each sea state (at intervals of $1 \mathrm{~s}$ for the energy period and $0.5 \mathrm{~m}$ for the significant wave height). At each point, there is a zone with significant energy potential. At these four points the largest-energy area corresponds to periods between 10 and $15 \mathrm{~s}$ and wave heights between 1.5 and $4 \mathrm{~m}$. Sea states with $H_{s}$ between 1.5 and $4 \mathrm{~m}$ account for a considerable fraction of the total energy (between $67 \%$ and $71 \%$, depending on the point), as do the sea states with $T_{e}$ between 10 and $15 \mathrm{~s}$ (between $58 \%$ and $62 \%$ depending on the point).

In Figures 8 and 9 the energy roses are also plotted, showing that at these points almost all the wave energy comes from the sector between NW and N, being NNW the most energetic direction.

Once the scatter diagrams have been obtained, the WEC energy output can be computed. As pointed out in Section 2.2, in this study two WECs whose power matrices are available in [14] have been considered: Pelamis [45] and Wave Dragon [46]. With their power matrices and the bin distribution of wave heights and periods, the power output is computed for the 2 WECs and the 23 studied points (Figures 10 and 11 and Table 4).

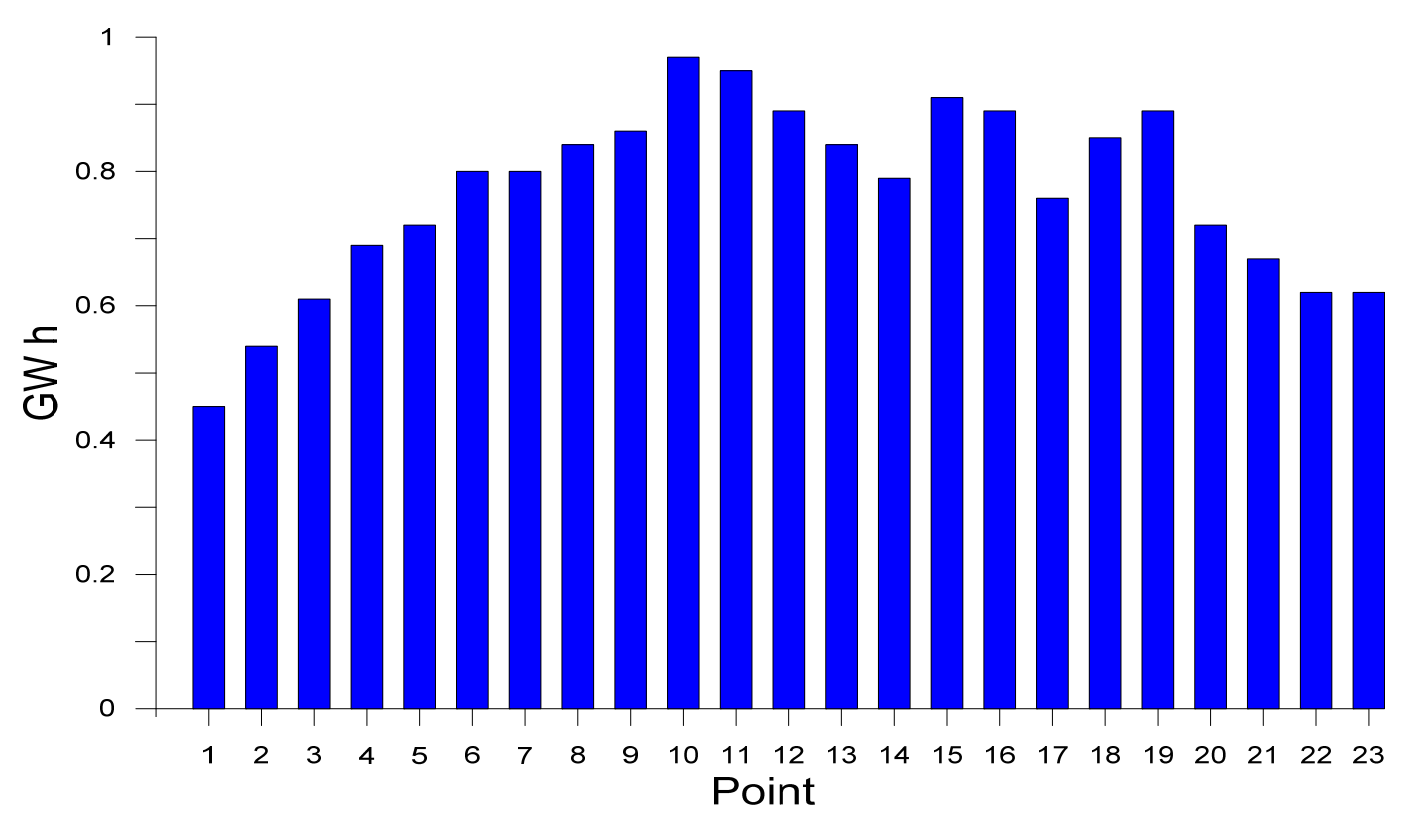

Figure 10. Annual wave energy output of the Pelamis WEC at the 23 studied points.

It is interesting to notice that the two points (P10 and P11) with the highest energy potential are also those giving the largest energy outputs for both WECs. In the case of the Wave Dragon the energy output exceeds $15 \mathrm{GW}$ h per year, while for the Pelamis the energy produced is slightly lower than 1 GW $h$ per year. With a decreasing productivity, the next most suitable locations for a Wave Dragon WEC are P9, P8 and P12, while for the Pelamis these positions are P15, P12, P16 and P19. The differences are probably due to the fact that Wave Dragon offers its best performance at wave periods between 10 and $15 \mathrm{~s}$ [14], while Pelamis gives the maximum output at wave periods between 6.5 and $11.5 \mathrm{~s}$ [14], being this last range more frequent in the southernmost part of the studied area.

As indicated in Section 2.2, an indicator of the WEC efficiency is the capacity factor, which gives the ratio between the actual energy produced by the WEC and the hypothetical energy that it could produce operating all the time at its maximum rated power. In Table 4 and Figure 12 the capacity factors for both devices at the 23 studied points are shown. In the central part of the studied coast, the Wave Dragon reaches capacity factors between $22 \%$ and $25.5 \%$ decreasing towards both ends. The highest values of the capacity factor for the Pelamis are slightly lower than $15 \%$ and vary 
between $12 \%$ and $14.7 \%$ in the central area of the Moroccan Atlantic coast, also decreasing towards the northern and southern ends.

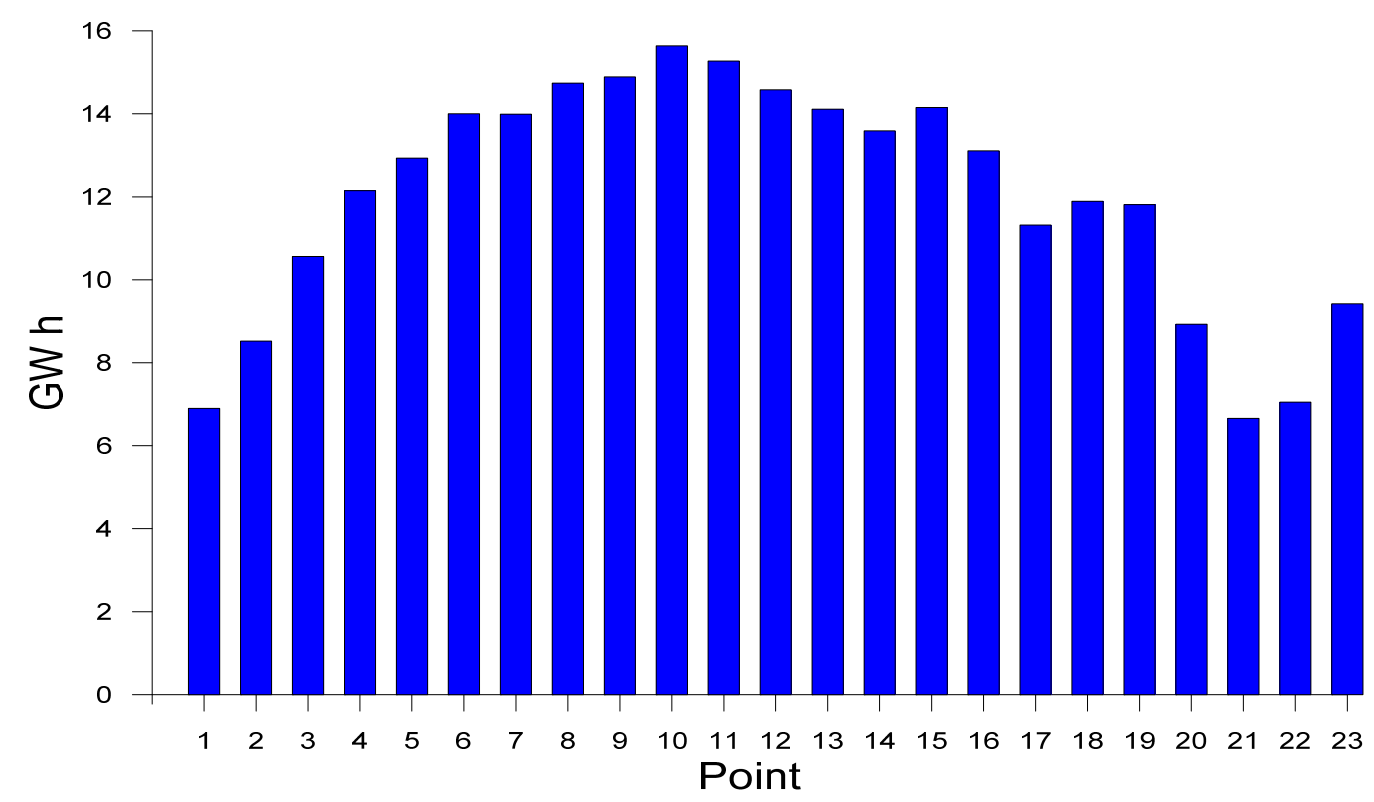

Figure 11. Annual wave energy output of the Wave Dragon WEC at the 23 studied points.

\begin{tabular}{|c|c|c|c|c|}
\hline \multirow{2}{*}{ Point } & \multicolumn{2}{|c|}{ Annual energy output (GW $\mathbf{~})$} & \multicolumn{2}{c|}{ Capacity factor (\%) } \\
\cline { 2 - 5 } & Wave Dragon & Pelamis & Wave Dragon & Pelamis \\
\hline P1 & 6.90 & 0.45 & 11.25 & 6.85 \\
\hline P2 & 8.52 & 0.54 & 13.89 & 8.22 \\
\hline P3 & 10.56 & 0.61 & 17.22 & 9.28 \\
\hline P4 & 12.15 & 0.69 & 19.81 & 10.50 \\
\hline P5 & 12.93 & 0.72 & 21.09 & 10.96 \\
\hline P6 & 14.00 & 0.80 & 22.83 & 12.18 \\
\hline P7 & 13.99 & 0.80 & 22.81 & 12.18 \\
\hline P8 & 14.74 & 0.84 & 24.04 & 12.79 \\
\hline P9 & 14.89 & 0.86 & 24.28 & 13.09 \\
\hline P10 & 15.64 & 0.97 & 25.51 & 14.76 \\
\hline P11 & 15.27 & 0.95 & 24.90 & 14.46 \\
\hline P12 & 14.58 & 0.89 & 23.78 & 13.55 \\
\hline P13 & 14.11 & 0.84 & 23.01 & 12.79 \\
\hline P14 & 13.59 & 0.79 & 22.16 & 12.02 \\
\hline P15 & 14.15 & 0.91 & 23.08 & 13.85 \\
\hline P16 & 13.11 & 0.89 & 21.38 & 13.55 \\
\hline P17 & 11.32 & 0.76 & 18.46 & 11.57 \\
\hline P18 & 11.89 & 0.85 & 19.39 & 12.94 \\
\hline P19 & 11.81 & 0.89 & 19.26 & 13.55 \\
\hline P20 & 8.93 & 0.72 & 14.56 & 10.96 \\
\hline P21 & 6.66 & 0.67 & 10.86 & 10.20 \\
\hline P22 & 7.05 & 0.62 & 11.50 & 9.44 \\
\hline P23 & 9.42 & 0.62 & 15.36 & 9.44 \\
\hline
\end{tabular}

Table 4. Annual energy output and capacity factors for both analyzed WECs at the 23 studied points. 


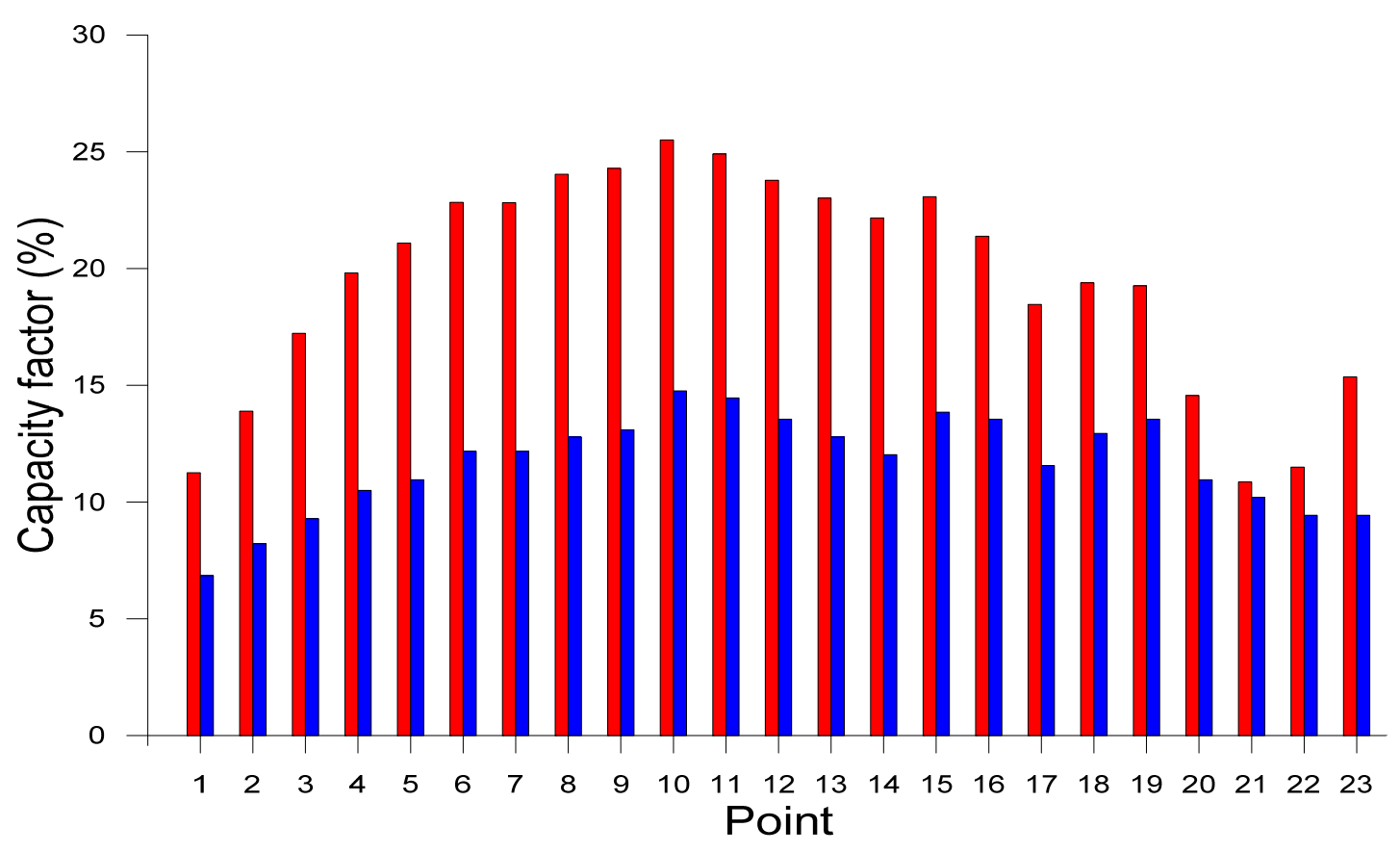

Figure 12. Capacity factors for both analyzed WECs: Wave Dragon (red) and Pelamis (blue) at the 23 studied points.

\subsection{WEC best location}

Besides the resource, there are further aspects of a site to be considered before selecting it to install a wave farm: its proximity to the coastline and to the electricity grid, its environmental impact at the site and on the coast, the possible interference with navigation or fishing activities, etc. [28]. From these factors, only those relative to the physical features of the site and to the wave energy potential and WEC performance have been considered herein to assess the best places for the deployment of the WECs. The remaining aspects fall outside the scope of this work, and have thus not been included in the analysis

With regard to the energy, the parameters considered are the wave energy potential, the temporal distribution of waves and the WEC output. The wave energy potential indicates the total amount of energy existing at a point. The temporal variation of waves is also relevant because a lower temporal variability will result in better WEC efficiency. Finally, the WEC output is essential because it indicates if the grouping of waves in certain bins (ranges of $H_{s}$ and $T_{e}$ ) is suitable for a specific WEC to produce more energy.

Regarding the site's physical features, the two parameters considered are the water depth and the distance to the coast. Water depth is important because all the WEC systems have a recommended working depth. Thus, for the two WECs studied here, the recommended depths of deployment are $>25 \mathrm{~m}$ for the Wave Dragon and $>50 \mathrm{~m}$ for the Pelamis [29], but greater depths increase the mooring costs. On the other hand, the distance to the coast can be assumed as a proxy for the connection costs (the larger the distance, the greater the costs since more cable is necessary).

The contribution of the wave power is assessed by computing the dimensionless normalized wave power index $P_{n}$ as:

$$
P_{n}=\frac{P_{i}}{P_{\max }}
$$


where $P_{i}$ is the average wave power at point $i$ and $P_{\max }$ is the maximum average wave power for all the reference points.

In a similar way, a normalized capacity factor $C_{f n}$ may be assessed for each considered WEC as:

$$
C_{f n}=\frac{C_{f i}}{C_{f \max }}
$$

where $C_{f i}$ is the capacity factor at point $i$ and $C_{\text {fmax }}$ is the maximum capacity factor for a certain WEC and all the reference points. This normalized factor ranks the sites as a function of the WEC efficiency.

To account for wave temporal variability, a parameter $T V$ is computed as the average of the three coefficients that measure the temporal variability: COV, MV and SV. After this, a normalized parameter $T V_{n}$ is computed, bearing in mind that high values of $T V$ should correspond to low values of $T V_{n}$, since they indicate less suitability for WEC deployment. To compute $T V_{n}$ the following expression is used:

$$
T V_{n}=1-\left(1-T V_{T H}\right) \frac{T V_{i}-T V_{\min }}{T V_{\max }-T V_{\min }}
$$

where $T V_{i}$ is the temporal variability parameter at point $i, T V_{\max }$ and $T V_{\min }$ are respectively the maximum and the minimum values at all the studied points and $T V_{T H}$ is a threshold value selected to give a minimum value to $T V_{n}$. From expression (11), if $T V_{i}=T V_{\min }$ then $T V_{n}=1$, while if $T V_{i}=$ $T V_{\text {max }}$ then $T V_{n}=T V_{T H}$. A value $T V_{T H}=0.3$ has been arbitrarily assumed.

The influence of the distance to the coast is taken into account in a similar way, computing a normalized distance index $d_{n}$ as:

$$
d_{n}=1-\left(1-d_{T H}\right) \frac{d_{i}-d_{\min }}{d_{\max }-d_{\min }}
$$

where $d_{i}$ is the distance to the coast of point $i, d_{\max }$ and $d_{\min }$ are respectively the maximum and minimum distances to the coast from all the studied points and $d_{T H}$ is a threshold value (assumed 0.3 ) to give a minimum value to $d_{n}$.

Finally, the water depth also intervenes in the suitability of a site for WEC deployment. To consider its contribution, a similar coefficient $h_{n}$ is computed as:

$$
h_{n}=1-\left(1-h_{T H}\right) \frac{h_{i}-h_{\min }}{h_{\max }-h_{\min }}
$$

where the meaning of the variables is the same as in the previous expressions, but referred to the water depth at each site. The main difference in this case is that the value of $h_{\min }$ is WECdependent. Since the water depth at all the locations is larger than the minimum recommended depth for the Wave Dragon WEC, for this converter $h_{\min }$ is set to the minimum depth (35 m, at P17). On the other hand, the minimum recommended depth for the Pelamis converter is $50 \mathrm{~m}$, so this is the value assumed for $h_{\min }$ for this WEC. At the locations shallower than $50 \mathrm{~m}$ (P17 and P20), $h_{\min }$ is set to zero for the Pelamis case. 
Once these five normalized coefficients have been computed, they are combined in a multi-criteria analysis. Here, the same weight has been assumed for all the factors, although different weights could be defined if the manager or stakeholder responsible for the site selection considers some factors to be more relevant than others. In the same way, the threshold values could also be changed. The analysis consists of calculating a simple WEC Location Suitability (WLS) index, as:

$$
W L S=P_{n}+C_{f n}+T V_{n}+d_{n}+h_{n}
$$

The WLS index takes into account all the considered factors and those points having a greater WLS value will be the more suitable for WEC deployment. This is a flexible index that allows an easy integration of other factors which might be identified as significant in the process of defining the convenience of deploying WECs at a certain location.

In Table 5 the values of the different coefficients integrating the WLS index are shown, while in Figure 13 the values of this suitability index at the 23 studied points are plotted. From these data, the most suitable points for WEC deployment are P11, P12 and P9 for both the Pelamis and the Wave Dragon converters. A second group of suitable points includes P16, P8 and P13, although the order differs between the Pelamis (P16, P8, P13) and the Wave Dragon (P8, P13, P16). Notice that $\mathrm{P} 10$, which has the largest wave energy potential, is not among the most suitable points for WEC installation.

\begin{tabular}{|c|c|c|c|c|c|c|c|}
\hline Point & W. Power & Distance & TV $_{\mathbf{n}}$ & \multicolumn{2}{|c|}{ Wave Dragon } & \multicolumn{2}{|c|}{ Pelamis } \\
\cline { 5 - 8 } & & & & Depth $\boldsymbol{h}_{\boldsymbol{n}}$ & $\mathbf{C}_{\text {fn }}$ & Depth $\boldsymbol{h}_{\boldsymbol{n}}$ & $\mathbf{C}_{\text {fn }}$ \\
\hline P1 & 0.31 & 1.00 & 0.30 & 0.96 & 0.44 & 0.98 & 0.46 \\
\hline P2 & 0.42 & 0.81 & 0.32 & 0.89 & 0.54 & 0.91 & 0.56 \\
\hline P3 & 0.59 & 0.75 & 0.36 & 0.86 & 0.68 & 0.88 & 0.63 \\
\hline P4 & 0.72 & 0.51 & 0.39 & 0.75 & 0.78 & 0.77 & 0.71 \\
\hline P5 & 0.77 & 0.61 & 0.44 & 0.84 & 0.83 & 0.86 & 0.74 \\
\hline P6 & 0.87 & 0.30 & 0.45 & 0.75 & 0.90 & 0.77 & 0.82 \\
\hline P7 & 0.86 & 0.75 & 0.50 & 0.96 & 0.89 & 0.98 & 0.82 \\
\hline P8 & 0.91 & 0.83 & 0.53 & 0.92 & 0.94 & 0.94 & 0.87 \\
\hline P9 & 0.96 & 0.78 & 0.53 & 0.96 & 0.95 & 0.98 & 0.89 \\
\hline P10 & 1.00 & 0.40 & 0.58 & 0.30 & 1.00 & 0.30 & 1.00 \\
\hline P11 & 0.96 & 0.81 & 0.60 & 0.95 & 0.98 & 0.97 & 0.98 \\
\hline P12 & 0.92 & 0.84 & 0.59 & 0.93 & 0.93 & 0.95 & 0.92 \\
\hline P13 & 0.88 & 0.83 & 0.59 & 0.87 & 0.90 & 0.89 & 0.87 \\
\hline P14 & 0.83 & 0.72 & 0.57 & 0.86 & 0.87 & 0.88 & 0.81 \\
\hline P15 & 0.87 & 0.58 & 0.63 & 0.87 & 0.90 & 0.89 & 0.94 \\
\hline P16 & 0.77 & 0.75 & 0.68 & 0.96 & 0.84 & 0.98 & 0.92 \\
\hline P17 & 0.64 & 0.88 & 0.69 & 1.00 & 0.72 & 0.00 & 0.78 \\
\hline P18 & 0.67 & 0.52 & 0.71 & 0.98 & 0.76 & 1.00 & 0.88 \\
\hline P19 & 0.65 & 0.30 & 0.75 & 0.91 & 0.76 & 0.93 & 0.92 \\
\hline P20 & 0.42 & 0.94 & 0.84 & 0.99 & 0.57 & 0.00 & 0.74 \\
\hline P21 & 0.26 & 0.37 & 1.00 & 0.53 & 0.43 & 0.53 & 0.69 \\
\hline P22 & 0.27 & 0.72 & 0.93 & 0.92 & 0.45 & 0.95 & 0.64 \\
\hline P23 & 0.62 & 0.62 & 0.91 & 0.53 & 0.60 & 0.62 & 0.64 \\
\hline
\end{tabular}

Table 5. Values of the parameters integrating the WLS index at the 23 studied points. 


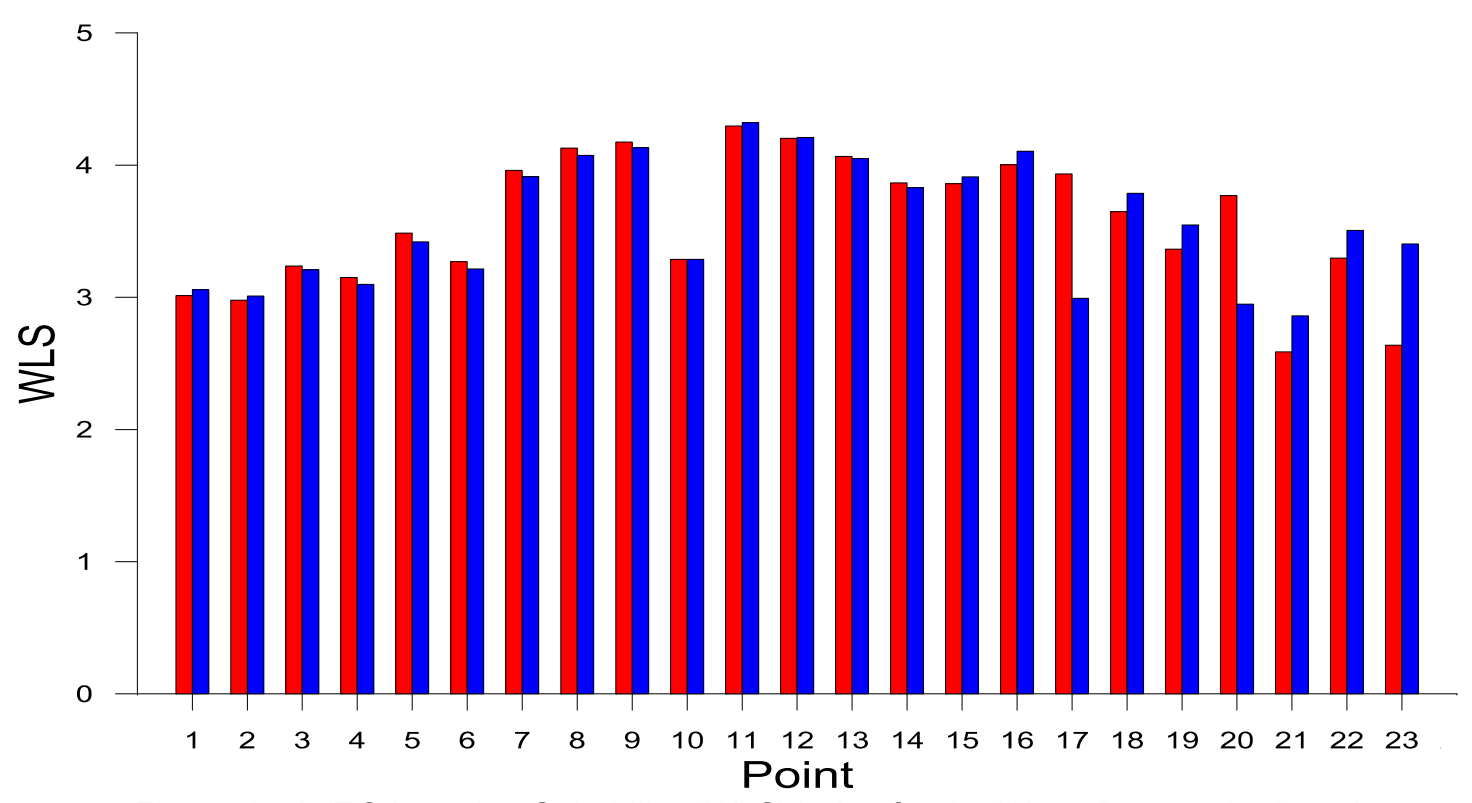

Figure 13. WEC Location Suitability (WLS) index for the Wave Dragon (red) and the Pelamis (blue) at the 23 studied points.

In summary, the best area in the Atlantic coast of Morocco for deploying the 2 studied WECs is the stretch comprised between P8 and P13, with the exception of P10, which is penalized by its depth and its distance to the coast.

\section{Conclusions}

Nowadays, and in spite of its large potential for wind and solar energies, only $10 \%$ of the energy production in Morocco is from renewable sources, mainly hydraulic and wind energy. In this study, the wave energy resource along its Atlantic coast is assessed using a 44-year series of data obtained from numerical modeling (hindcasting).

The wave power is analyzed using data from 23 points between latitudes $27^{\circ} \mathrm{N}$ and $35^{\circ} 45^{\prime} \mathrm{N}$. The average wave power obtained is considerable (up to $30 \mathrm{~kW} / \mathrm{m}$ with average annual wave energy up to $262 \mathrm{MW} \mathrm{h/m}$ ) and slightly lower than at the neighboring Canary Islands.

The spatial distribution of wave energy along Morocco's Atlantic coast shows a large variability, with a high-energy stretch in the central part of this area (between latitudes $29^{\circ} 30^{\prime} \mathrm{N}$ and $34^{\circ} \mathrm{N}$ ). On the contrary, at both ends of the coast the wave energy potential is lower due to the shadow effects generated by the Iberian Peninsula in the North and the Canary Islands in the South. About $60 \%$ of the energy is concentrated in wave periods between 10 and $15 \mathrm{~s}$ and about $70 \%$ in wave heights between 1.5 and $4 \mathrm{~m}$. Regarding the wave directionality, waves from N, NNW and NW are the most energetic.

The temporal variability of wave energy along the Morocco's Atlantic coast shows a clear seasonal pattern, with a high-energy winter $(43 \%$ in average), a mild summer $(10 \%)$ and intermediate-energy spring and autumn (with $26 \%$ and $21 \%$ respectively). There is also a significant monthly variability, with January being the highest-energy month (followed by December and February) and July (followed by August and June) the mildest one. 
Taking into account the power matrices of two WECs (Pelamis and Wave Dragon), the energy output and the capacity factor are computed at the 23 studied points. Finally, a multi-criteria analysis is carried out considering five different factors, combined into a single WEC Location Suitability (WLS) index, in order to select the best places for WEC deployment. These factors are: the wave power at the point, the WEC capacity factor, the energy temporal variability, the distance to the coast and the water depth at the point. The analysis of the WLS index allows identifying points P11, P12 and P9, in the central stretch of the study area, as the optimal places for WEC installation along the Moroccan Atlantic coast.

\section{Acknowledgements}

This study was funded by the research project "Desarrollo de una herramienta de alta resolución como soporte al diseño, colocación y explotación de instalaciones para energías marinas (DARDO)" (ref. ENE2012-38772-C02-02) funded by the Spanish Ministry of Economy and Competitiveness. The authors are also grateful to the Spanish Port Authority (Organismo Público Puertos del Estado) for providing the wave data. The support of the Secretaria d'Universitats i Recerca del Dpt. d'Economia i Coneixement de la Generalitat de Catalunya (Ref 2014SGR1253) is also acknowledged.

\section{References}

[1] ICEX. El Mercado de las energías renovables en Marruecos. Technical Report, ICEX, Ministerio de Economía y Competitividad, Madrid, 2014.

[2] Nfaoui H, Bahraui J, Darwish AS, Sayigh AAM. Wind energy potential in Morocco. Renewable Energy 1991;1:1-8.

[3] Nfaoui H, Essiarab H, Sayigh AAM. A stochastic Markov chain model for simulating wind speed time series at Tangiers, Morocco. Renewable Energy 2004;8:1407-1418.

[4] Ouammi A, Sacile R, Zejli D, Mimet A, Benchifra R. Sustainability of a wind power plant: Application to different Moroccan sites. Energy 2010;35:4226-4236.

[5] Zeroual A, Ankrim M, Wilkinson AJ. Stochastic modelling of daily global solar radiation measured in Marrakesh, Morocco. Renewable Energy 1995;6:787-793.

[6] Nfaoui H, Buret J. Estimation of daily and monthly direct, diffuse and global solar radiation in Rabat (Morocco). Renewable Energy 1993;3:923-930.

[7] Liberti L, Carillo A, Sannino G. Wave energy resource assessment in the Mediterranean, the Italian perspective. Renewable Energy 2013;50:938-949.

[8] Arena F, Laface V, Malara G, Romolo A, Viviano A, Fiamma V, Sannino G, Carillo A. Wave climate analysis for the design of wave energy harvesters in the Mediterranean Sea. Renewable Energy 2015;77:125-141.

[9] Iglesias G, Carballo R. Wave power for La Isla Bonita. Energy 2010;35:513-521.

[10] Sierra JP, González-Marco D, Sospedra J, Gironella X, Mösso C, Sánchez-Arcilla A. Wave energy resource assessment in Lanzarote (Spain). Renewable Energy 2013;55:480-489. 
[11] Iglesias G, Carballo R. Wave resource in El Hierro an island towards energy self-sufficiency. Renewable Energy 2011;36:689-698.

[12] Gonçalves M, Martinho P, Guedes Soares C. Assessment of wave energy in the Canary Islands. Renewable Energy 2014;68:774-784.

[13] Rusu E, Pilar P, Guedes Soares C. Evaluation of the wave conditions in Madeira Archipelago with spectral models. Ocean Engineering 2008;35:1357-1371.

[14] Rusu E, Guedes Soares C. Wave energy pattern around the Madeira Islands. Energy 2012;45:771-785.

[15] Rusu L, Guedes Soares C. Wave energy assessments in the Azores Islands. Renewable Energy 2012;45:183-196.

[16] Rusu E, Onea F. Estimation of the wave energy conversion efficiency in the Atlantic Ocean close to the European islands. Renewable Energy 2016;85:687-703.

[17] van Nieuwkopp JCC, Smith HCM, Smith GH. Wave resource assessment along the Cornish coast (UK) from a 23-year hindcast dataset validated against buoy measurements. Renewable Energy 2013;58:1-14.

[18] Rute Bento A, Martinho P, Guedes Soares C. Numerical modelling of the wave energy in Galway Bay. Renewable Energy 2015;78:457-466.

[19] Venugopal V, Nemalidinne R. Wave resource assessment for Scottish waters using a large scale North Atlantic spectral wave model. Renewable Energy 2015;76:503-525.

[20] Gonçalves M, Martinho P, Guedes Soares C. Wave energy conditions in the western French coast. Renewable Energy 2014;62:155-163.

[21] Guillou N, Chapalain G. Numerical modelling of nearshore wave energy resource in the Sea of Iroise. Renewable Energy 2015;83:942-953.

[22] Rusu E, Guedes Soares C. Numerical modelling to estimate the spatial distribution of the wave energy in the Portuguese nearshore. Renewable Energy 2009;34:1501-1516.

[23] Mendes RPG, Calado MRA, Mariano SJPS. Wave energy potential in Portugal- Assessment based on probabilistic description of ocean waves parameters. Renewable Energy 2012;47:1-8.

[24] Mota P, Pinto JP. Wave energy potential along the western Portuguese coast. Renewable Energy 2014;71:8-17.

[25] Iglesias G, López M, Carballo R, Castro A, Fraguela JA, Frigaard P. Wave energy potential in Galicia (NW Spain). Renewable Energy 2009;34:2323-2333.

[26] Iglesias G, Carballo R. Wave energy potential along the Death Coast (Spain). Energy 2009;34:1963-1975.

[27] Iglesias G, Carballo R. Wave energy resource in the Estaca de Bares area (Spain). Renewable Energy 2010;35:1574-1584.

[28] Iglesias G, Carballo R. Choosing the site for the first wave farm in a region: A case study in the Galician Southwest (Spain). Energy 2011;36:5525-5531.

[29] Rusu L, Onea F. Assessment of the performances of various wave energy converters along the European continental coasts. Energy 2015;82:889-904. 
[30] Iglesias G, Carballo R. Wave energy and nearshore hot spots: The case of the SE Bay of Biscay. Renewable Energy 2010;35:2490-2500.

[31] Iglesias G, Carballo R. Offshore and inshore wave energy assessment: Asturias (N Spain). Energy 2010;35:1964-72.

[32] Henriques JCC, Candido JJm Pontes MT, Falcao AFO. Wave energy resource assessment for a breakwater-integrated oscillating water column plant at Porto, Portugal. Energy 2013;63:52-60.

[33] Iglesias G, Carballo R. Wave farm impact: the role of farm-to-coast distance. Renewable Energy 2014;69:375-385.

[34] Pinet P. Invitation to Oceanography. Colgate University 2006.

[35] Gunn K, Stock-Williams C. Quantifying the global wave power resource. Renewable Energy 2012;44:296-304.

[36] Guedes Soares C. Hindcast of dynamic processes of the ocean and coastal areas of Europe. Coastal Engineering 2008;55:825-6.

[37] Pilar P, Guedes Soares C, Carretero JC. 44-year wave hindcast for the north east Atlantic European coast. Coastal Engineering 2008;55:861-71.

[38] WAMDI Group. The WAM model e a third generation ocean wave prediction model. Journal of Physical Oceanography 1988;18:1775-810.

[39] Jacob D. A note to the simulation of the annual and inter-annual variability of the water budget over the Baltic Sea drainage basin. Meteorology and Atmospheric Physics 2001;77:61-73.

[40] Musić S, Nicković S. 44-year wave hindcast for the Eastern Mediterranean. Coastal Engineering 2008;55:872-80.

[41] Sotillo MG, Ratsimandresy AW, Carretero JC, Bentamy A, Valero F, González-Rouco F. A high resolution 44-year atmospheric hindcast for the Mediterranean Basin: contribution to the regional improvement of global reanalysis. Climate Dynamics 2005;25:219-36.

[42] Ratsimandresy AW, Sotillo MG, Carretero JC, Álvarez-Fanjul E, Haiji HA. 44- year high resolution ocean and atmospheric hindcast for the Mediterranean Basin developed within the HIPOCAS project. Coastal Engineering 2008;55:827-42.

[43] Cornett AM. A global wave energy resource assessment. In International Offshore and Polar Engineering Conference, Vancouver, Canada 2008; pp. 318-326.

[44] Boronowski S, Wild P, Rowe A, van Kooten GC. Integration of wave power in Haida Gwaii. Renewable Energy 2010;35:2415-242.

[45] Henderson R. Design, simulation and testing of a novel hydraulic power take-off system for the Pelamis wave energy converter. Renewable Energy 2006;31:271-283.

[46] Kofoed JP, Frigaard P, Friis-Madsen E, Sørensen HC. Prototype testing of the wave energy converter Wave Dragon. Renewable Energy 2006;31:181-189.

[47] Guillou N. Evaluation of wave energy potential in the Sea of Iroise with two spectral models. Ocean Engineering 2015;106:141-151.

[48] Contestabile $P$, Ferrante V, Vicinanza $D$. Wave energy resource along the Coast of Santa Catarina (Brazil). Energies 2015;8:14219-14243. 